\title{
Avaliação da linguagem e aspectos visuais de painéis interpretativos turísticos para geomonumentos e outros elementos geopatrimoniais do corede campanha, RS, Brasil
}

\author{
Evaluation of speech and visual aspects of touristic interpretive panels for geosites \\ and other geoheritage elements of the corede campanha territory, RS, Brasil
}

\section{André Weissheimer de Borbal; Milene Ferreira Miletto"; Ana Paula Souza Corrêa"II; Vinícius Lenz MottaIV; Marta Paula Fischerv; Thainara Dalmazo BrunhauserVI; Renato Pereira Lopes ${ }^{\text {III; }}$ Felipe Guadagnin VIII}

\begin{abstract}
Resumo
Painéis interpretativos são meios de comunicação visual largamente utilizados em estratégias ligadas ao geopatrimônio. Sua linguagem e aspectos visuais podem ser decisivos para uma boa comunicação com os visitantes e a comunidade local. Este trabalho traz uma avaliação de painéis interpretativos preliminares, idealizados para o território do COREDE Campanha, realizada por estudantes do ensino fundamental (séries finais) do Instituto Municipal de Educação de Caçapava do Sul, os quais analisaram os aspectos gráficos e de conteúdo das interpretações. Com base nessas avaliações, houve mudanças nos tamanhos e cores das letras do texto, na cor de fundo e nas cores de elementos gráficos específicos, bem como no conteúdo de alguns painéis, especialmente naqueles referentes à temática da paleontologia e da preguiça-gigante.
\end{abstract}

Palavras-chave: Geoconservação; Geopatrimônio; Geoturismo; Interpretação

\begin{abstract}
Interpretive panels are visual communication means widely used in geoheritage-related strategies. Their speech and visual aspects can be decisive for a good communication with tourists and local communities. This paper brings an evaluation of preliminarily-designed interpretive panels for the COREDE Campanha territory. Evaluation was performed by elementary school students from Caçapava do Sul, who have analyzed interpretive graphics and written content. Based on those evaluations, changes have been implemented in written text lettering size and color, background color, and in specific graphic elements colors. There have also been changes in written text content in some panels, especially in those subjects related to paleontology and the fossil ground sloths.
\end{abstract}

Keywords: Geoconservation; Geoheritage; Geotourism; Interpretation

Universidade Federal de Santa Maria, Santa Maria, RS, Brasil, https://orcid.org/0000-0002-0009-6634- awborba.geo@gmail.com Secretaria Municipal de Educação, Caçapava do Sul, RS, Brasil - https://orcid.org/0000-0001-7784-3936 - mmiletto@hotmail.com

III Universidade Federal do Pampa, Unipampa, Caçapava do Sul, RS, Brasil - https://orcid.org/0000-0002-8579-5732 - anacorrea.cp@gmail.com

IV Universidade Federal de Santa Maria, Santa Maria, RS, Brasil, https://orcid.org/0000-0002-1509-1860 - viniciusmottaufsm@gmail.com

Universidade Federal de Santa Maria, Santa Maria, RS, Brasil, https://orcid.org/0000-0002-4810-1674 - martapaulafischer@gmail.com

v1 Universidade Federal de Santa Maria, Santa Maria, RS, Brasil, https://orcid.org/0000-0003-4641-9707 - tbrunhauser@yahoo.com

VII Universidade Federal de Santa Catarina, , Florianópolis, SC, Brasil - https://orcid.org/0000-0002-4865-6426 - paleonto_furg@yahoo.com.br

VIII Universidade Federal do Pampa, Caçapava do Sul, RS, Brasil, https://orcid.org/0000-0003-0795-4205 - felipe.guada@yahoo.com.br 


\section{INTRODUÇÃO}

A interpretação geopatrimonial e ambiental é uma atividade de grande relevância para projetos de geoconservação, geoturismo e valorização da paisagem (MOREIRA, 2012, 2014; BAZÁN, 2013, 2014; SELL, 2017). Trilhas guiadas e autoguiadas, folhetos e cadernos, guias turísticos, meios audiovisuais interativos e painéis interpretativos são alguns dos meios de interpretação mais utilizados para essa atividade de divulgação e educação ambiental e patrimonial (NOVA SCOTIA, 2008). Dependendo das condições físicas, da permanência da mensagem e do afluxo de visitantes em determinado local durante o ano, a instalação de painéis interpretativos fixos pode ser uma ferramenta eficiente para comunicar ao público sobre as características geopatrimoniais, ambientais e paisagísticas de um local ou conteúdo. Painéis interpretativos têm sido propostos, desenhados e implantados em contextos geopatrimoniais tão diversos quanto a Pedra Furada, em Jericoacoara, Ceará (MEIRA et al., 2016), ou o Buraco do Padre, em Ponta Grossa, Paraná (LUZ \& MOREIRA, 2010).

O Conselho Regional de Desenvolvimento da região da Campanha (COREDE Campanha), na chamada 'metade sul' do Rio Grande do Sul, é um território de mais de 18 mil quilômetros quadrados, composto por sete municípios: Aceguá, Bagé, Candiota, Caçapava do Sul, Dom Pedrito, Hulha Negra e Lavras do Sul. Na Consulta Popular de 2015, a população do COREDE Campanha definiu o geoturismo como uma de suas prioridades, o que ensejou a presente pesquisa.

Um levantamento já finalizado (BORBA et al., 2019a) identificou oito grandes áreas complexas como alvos de implantação de infraestrutura geoturística: (1) o alto de Caçapava do Sul; (2) a Serra de Santa Bárbara; (3) a Serra do Segredo; (4) as Pedras das Guaritas; (5) a área de Lagoa da Meia-Lua/Palma; (6) o Rincão do Inferno; (7) a Casa de Pedra ou Pico do Morcego; e (8) o platô do Taquarembó. Da mesma forma, foram avaliados alguns contextos, elementos ex situ e identidades que também merecem interpretação e divulgação: (9) os contextos do cráton La Plata e do ofiolito Cerro Mantiqueiras; (10) o carvão mineral e os fósseis do Permiano, sobretudo na porção sul do COREDE; (11) os fósseis do Pleistoceno, em Caçapava do Sul, 
especialmente as preguiças-gigantes; assim como (12) a identidade e a memória mineira e garimpeira da cidade de Lavras do Sul e da vila Minas do Camaquã, em Caçapava do Sul (BORBA et al., 2019b).

Entre as ações planejadas para a divulgação do geoturismo no âmbito do COREDE Campanha, estava a idealização, redação, diagramação, impressão e publicação de painéis interpretativos para os geomonumentos mais acessíveis e mais visitados, bem como para as praças urbanas mais importantes de todos os sete municípios do território. Para avaliar os painéis confeccionados, de forma prévia à sua finalização e publicação, foi realizado um teste de linguagem e do aspecto visual dos painéis com 72 estudantes de sexto, sétimo e oitavo anos do ensino fundamental (jovens entre 11 e 14 anos de idade) do Instituto Municipal de Educação Augusta Maria de Lima Marques, em Caçapava do Sul. Os resultados aqui obtidos, sempre cotejados à experiência acumulada pela ciência da interpretação (TILDEN, 1957; NOVA SCOTIA, 2008; MOREIRA, 2012, 2014, BAZÁN, 2013, 2014) foram decisivos para o desenho final dos painéis interpretativos implantados no COREDE Campanha.

\section{INTERPRETAÇÃO AMBIENTAL/GEOPATRIMONIAL E PAINÉIS INTERPRETATIVOS}

A interpretação constitui uma atividade educativa que, mediante o contato direto com o objeto ou se utilizando de meios ilustrativos, busca levar ao visitante um significado e o estabelecimento de uma ligação afetiva com o conteúdo interpretado, podendo inclusive levar o ser humano a compreender seu lugar no ambiente (TILDEN, 1957; ALDRIDGE, 1973). Essa atividade educativa baseia-se na tradução da linguagem complexa da natureza para uma linguagem mais acessível, sem perda de significado ou precisão, criando assim sensibilidade, consciência, entusiasmo, entendimento e compromisso com a conservação daquele conteúdo (RISK, 1982). Nas palavras de Tilden (1957), considerado o 'pai da interpretação', busca-se "por meio da interpretação, o entendimento; por meio do entendimento, o apreço; por meio do apreço, a proteção" (TILDEN, 1957, p. 38). É importante salientar também o alerta de 
Morales-Miranda (1983) de que a interpretação deve "educar sem que o público sinta que é objeto de uma atividade educativa", e que deve "despertar a curiosidade mais do que satisfazê-la" (MORALES-MIRANDA, 1983, p. 17).

De acordo com Nova Scotia (2008), os benefícios dos painéis interpretativos são: (a) gerar consciência e orgulho na comunidade, estimulando as pessoas a se envolverem nos projetos; (b) oferecer uma nova experiência aos visitantes, ao mesmo tempo que os informa e educa; (c) estimular os visitantes a permanecerem mais tempo e deixarem mais dinheiro na comunidade local; (d) poder alertar para problemas de segurança; e (e) fornecer uma fonte de informação permanente. Inclusive por sua durabilidade, o ideal é que a mensagem seja também relativamente permanente por um período de 5 a 10 anos, o que não é problema para a mensagem da geodiversidade e para os atrativos geoturísticos aqui focalizados. No entanto, é importante salientar que os painéis interpretativos, por seu custo relativamente alto, não constituem o meio ideal quando houver possibilidade de baixa visitação por ser aquele local remoto ou ter dificuldades de acesso (NOVA SCOTIA, 2008).

A linguagem ideal para um painel interpretativo inclui as seguintes características, de acordo com Nova Scotia (2008): (a) escrever como se estivesse falando diretamente ao visitante; (b) convidar o visitante a usar seus sentidos, com sugestões como "olhe", "ouça", "procure", entre outras maneiras de chamar sua atenção e fazê-lo explorar o entorno; (c) utilizar perguntas comuns dos visitantes, e respondê-las; (d) utilizar maneiras visualmente expressivas de transmitir as ideias; (e) contar histórias, conectando o visitante emocionalmente aos personagens; (f) manter ao máximo o painel atemporal; e (g) usar uma linguagem neutra, em termos de gênero.

Além dessas recomendações, um painel de $60 \mathrm{~cm}$ x $90 \mathrm{~cm}$ não deveria ter mais de 200 palavras, enquanto um painel de $90 \mathrm{~cm}$ x $120 \mathrm{~cm}$ não deveria ultrapassar 350 palavras (NOVA SCOTIA, 2008). Também é importante a recomendação de que o painel seja escrito em uma linguagem adequada a um nível de compreensão de um adolescente de 13 anos (HOSE, 1999) ou, na avaliação dos canadenses, para o nível de 
escolaridade (grade) 6 a 8, que corresponde à faixa etária de 11 a 13 anos (NOVA SCOTIA, 2008). Por fim, deve-se evitar o uso de cores vibrantes ou fluorescentes, bem como combinações prejudiciais ao público daltônico (verde, vermelho, laranja, marrom, azul e amarelo em sobreposição) ou imagens de fundo muito 'poluídas' em termos de elementos gráficos.

\section{METODOLOGIA}

Para a avaliação preliminar, sempre considerando os princípios da interpretação e suas melhores práticas (TILDEN, 1957; BAZÁN, 2014; SELL, 2017), foram idealizados, desenhados, redigidos, diagramados e impressos em papel quatro painéis interpretativos sobre geomonumentos ou elementos geopatrimoniais presentes em Caçapava do Sul, no território do COREDE Campanha: (1) um painel focalizando a formação das rochas da Pedra do Segredo, com base em informações de Borba et al. (2016), orientado na horizontal ('paisagem'), medindo $60 \mathrm{~cm}$ de altura e $120 \mathrm{~cm}$ de largura, com informações em português e castelhano, uma fotografia do geomonumento como marca d'água, sobreposta por uma lâmina transparente de cor alaranjada/amarelada, e em primeiro plano algumas fotografias de aves que podem ser observadas no local (Fig. 1); (2) um painel focalizando a formação das rochas das Pedras das Guaritas, também com base em Borba et al. (2016), de formato quadrado, medindo $100 \mathrm{~cm}$ tanto na altura quanto na largura, também com imagem de fundo em marca d'água com transparência alaranjada, com textos dispostos em linhas longas, dividido sempre na horizontal (Fig. 2); (3) um painel focalizando o patrimônio geo-mineiro da vila Minas do Camaquã, com base no trabalho de Domingues (2016), de formato quadrado, medindo também $100 \mathrm{~cm}$ em altura e largura, com uma imagem do Cine Rodeio como marca d'água e textos divididos em três colunas verticais (Fig. 3), alinhados conforme o setor; e (4) um painel focalizando as características do megatério, a maior das preguiças-gigantes, quadrado $(100 \mathrm{~cm} \mathrm{x}$ $100 \mathrm{~cm})$, sem marca d'água, com fundo de cor alaranjada sólida e textos distribuídos 
em duas colunas justificadas (Fig. 4). Todos os painéis tinham três faixas horizontais, sendo a superior de cor castanha e a inferior de cor azul petróleo, com a faixa do meio sempre alaranjada, além de alguns círculos azuis com texto em seu interior (no painel da Pedra do Segredo, Fig. 1). Isso proporcionou uma ampla gama de combinações de cores, pois havia textos em amarelo, branco e marrom escuro, sempre em fonte 'Candara', com o corpo do texto em fonte de tamanho 40, títulos maiores e textos em castelhano (exclusivamente no painel da Pedra do Segredo, Fig.

1) em tamanho menor.

Figura 1 - Painel preliminar referente ao geomonumento Pedra do Segredo, apresentado aos estudantes para avaliação de linguagem e aspecto visual. O painel traz textos em português e castelhano (fonte menor), distribuídos e alinhados conforme o setor em que se encontram. Traz ainda informações sobre a geodiversidade e sobre aves possíveis de serem observadas no local interpretado

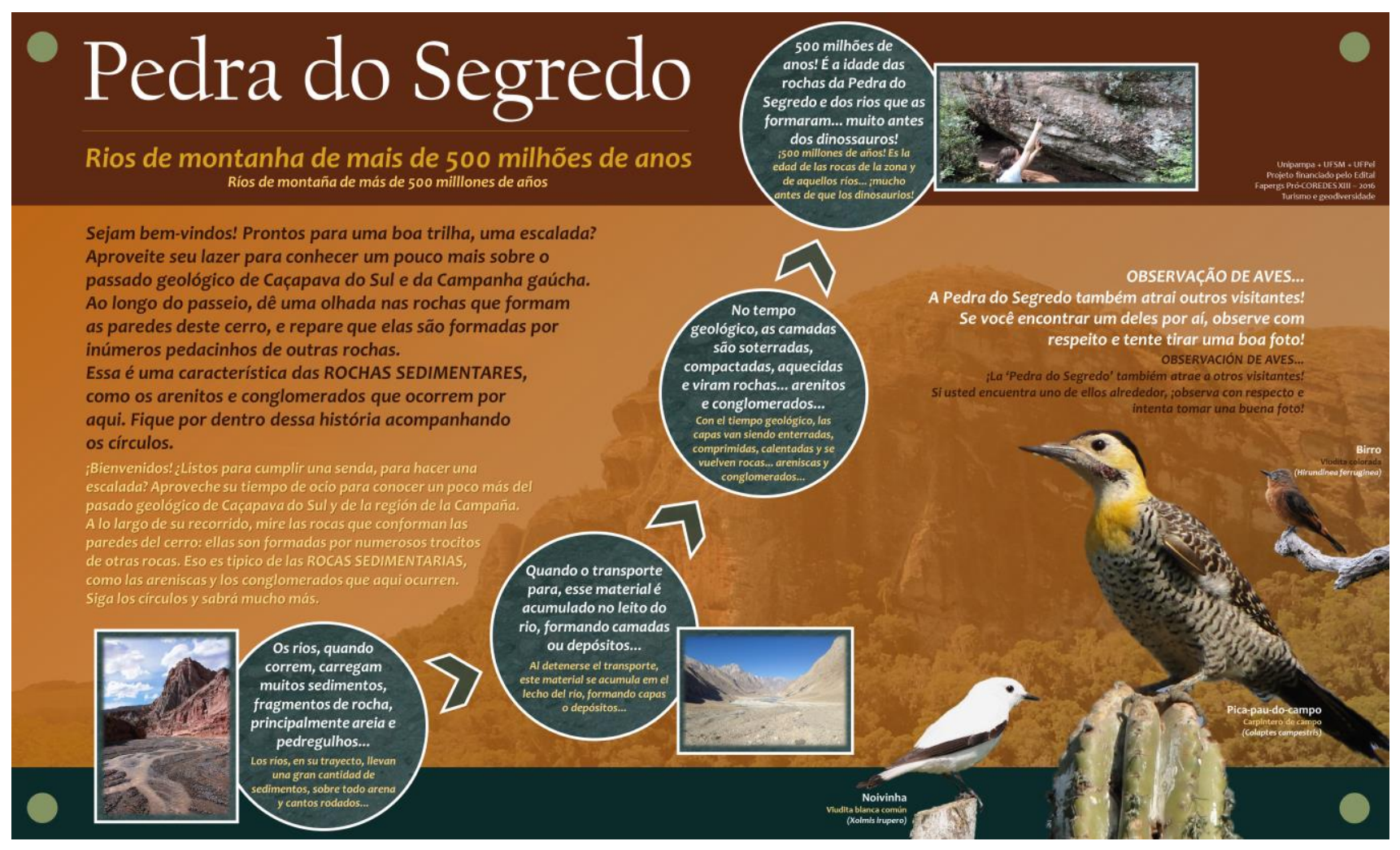

Fonte: Elaborado pelos autores em 2017 
Figura 2 - Painel preliminar referente ao geomonumento Pedras das Guaritas, apresentado aos estudantes para avaliação de linguagem e aspecto visual. O painel traz textos exclusivamente em português, em cores claras (branco e amarelo claro) sobre um fundo de cor castanha-alaranjada, com compartimentação e disposição horizontal das informações

\section{geodiversidade \\ e turismo \\ Pedras das Guaritas}

Seja bem-vindo a um dos geomonumentos mais

importantes do Rio Grande do Sul!

Origem das rochas

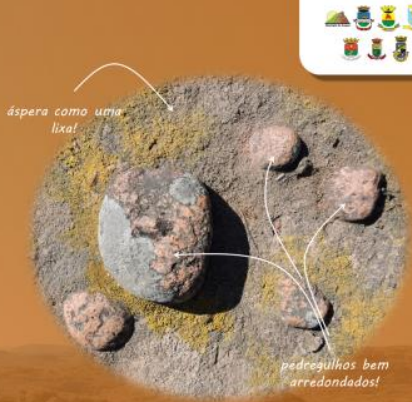

Ao caminhar pelas trilhas, dê uma olhada nas rochas. Observe seus detalhes. Toque nas rochas. Você vai perceber que elas são ásperas, como se fossem uma lixa. Isso é porque essas rochas são formadas por grãos de areia: são arenitos.

Outra coisa importante: você vai encontrar, ao longo do caminho, muitos pedregulhos arredondados, encravados nas rochas; fazendo parte delas.

Isso nos mostra que esses materiais foram depositados por grandes rios, que transportavam areia e pedregulhos vindos das montanhas. Aqueles rios não existem mais; aquelas montanhas não existem mais. Mas as rochas das Guaritas são o testemunho de que esses ambientes existiram. Há 500 milhổes de anos!
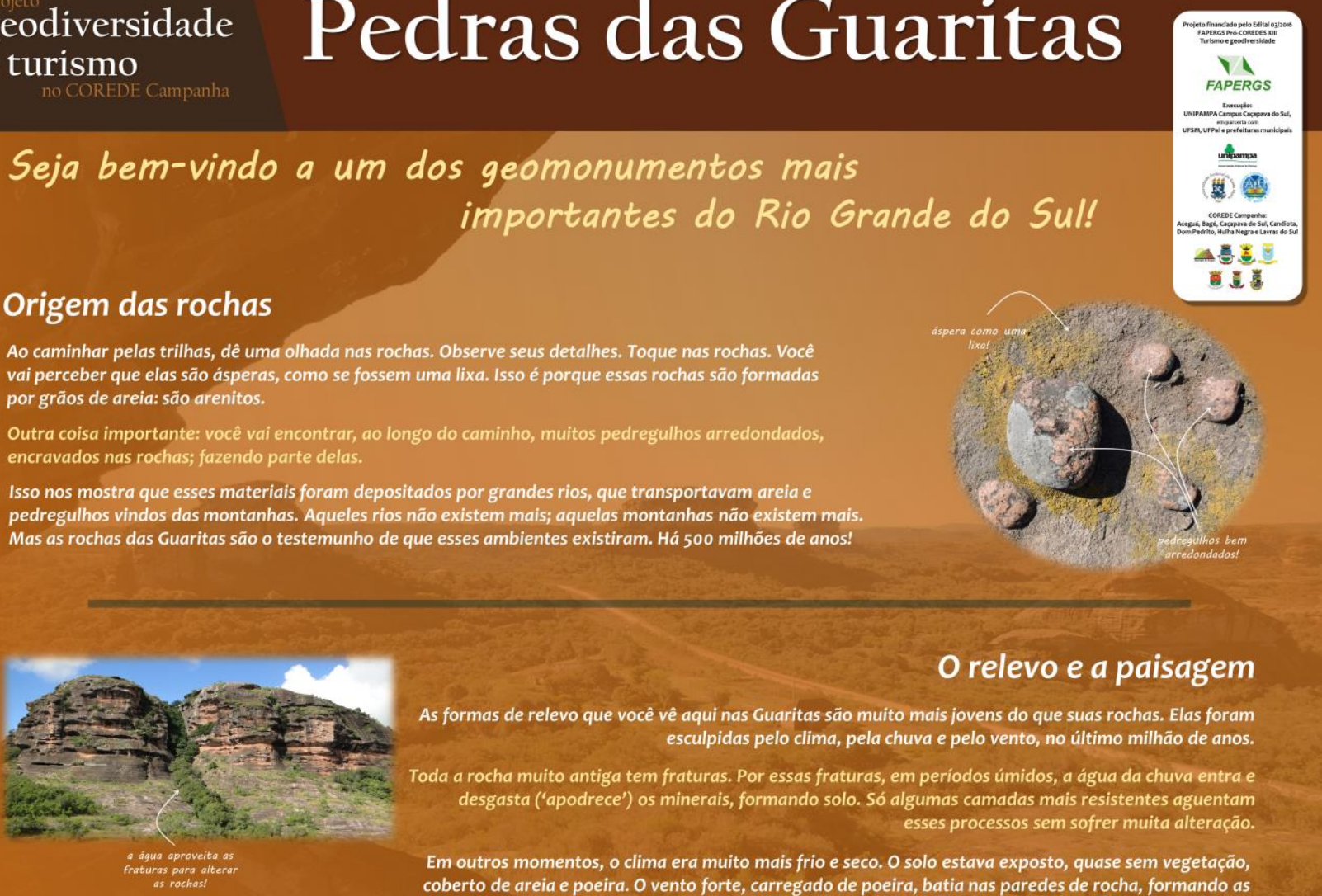

O relevo e a paisagem

As formas de relevo que você vê aqui nas Guaritas são muito mais jovens do que suas rochas. Elas foram esculpidas pelo clima, pela chuva e pelo vento, no último milhäo de anos.

Toda a rocha muito antiga tem fraturas. Por essas fraturas, em periodos úmidos, a água da chuva entra e desgasta ('apodrece') os minerais, formando solo. Só algumas camadas mais resistentes aguentam esses processos sem sofrer muita alteração.

Em outros momentos, o clima era muito mais frio e seco. O solo estava exposto, quase sem vegetação, coberto de areia e poeira. O vento forte, carregado de poeira, batia nas paredes de rocha, formando as cavidades ('buracos') chamadas de 'janelas de abrasão eólica'.

Outro elemento importante dessa paisagem são os cactos. Eles também são testemunhos de épocas mais secas, quando o pampa estava conectado ao cerrado. E o toque final é a presença dos rebanhos de cabras, animal de criação muito bem adaptado aos cerros ingremes das Pedras das Guaritas.
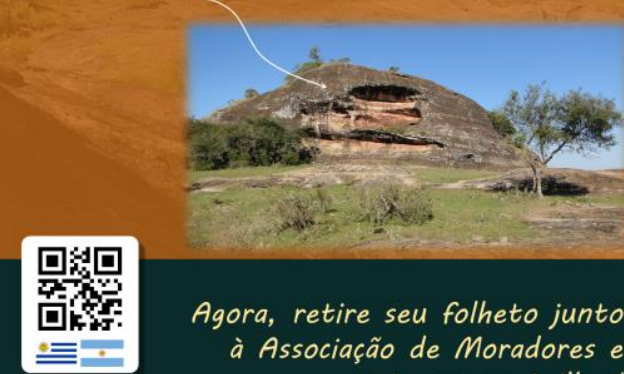

Agora, retire seu folheto junto à Associação de Moradores e curta nossas trilhas!

Fonte: Elaborado pelos auto***1111111116666666res em 2017 
Figura 3 - Painel preliminar referente ao patrimônio geo-mineiro da Vila Minas do Camaquã, em Caçapava do Sul, apresentado aos estudantes para avaliação de linguagem e aspecto visual. O painel traz textos exclusivamente em português, em cores claras (branco e amarelo claro) sobre um fundo de cor castanha-alaranjada, com compartimentação vertical das informações em três colunas, e alinhamento variando conforme o setor do painel

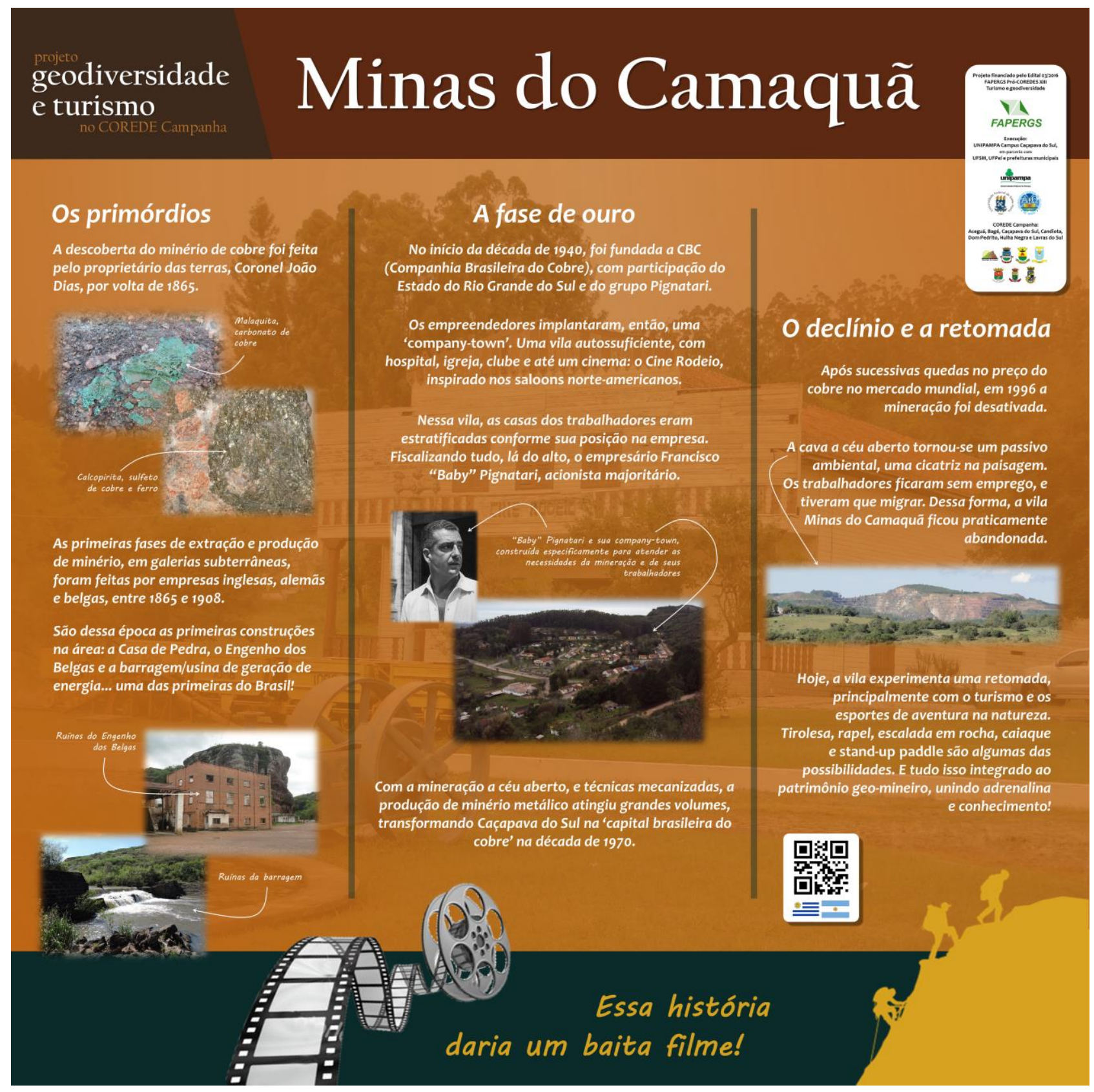

Fonte: Elaborado pelos autores em 2017 
Figura 4 - Painel preliminar referente às preguiças-gigantes, principal representante da megafauna do Pleistoceno na área de abrangência do COREDE Campanha, apresentado aos estudantes para avaliação de linguagem e aspecto visual. O painel traz textos exclusivamente em português, em cor branca sobre um fundo de cor castanha-alaranjada, com alinhamento justificado. Um detalhe relevante é a ausência, exclusivamente neste painel, de fotografia de fundo como 'marca d'água', presente nos demais painéis

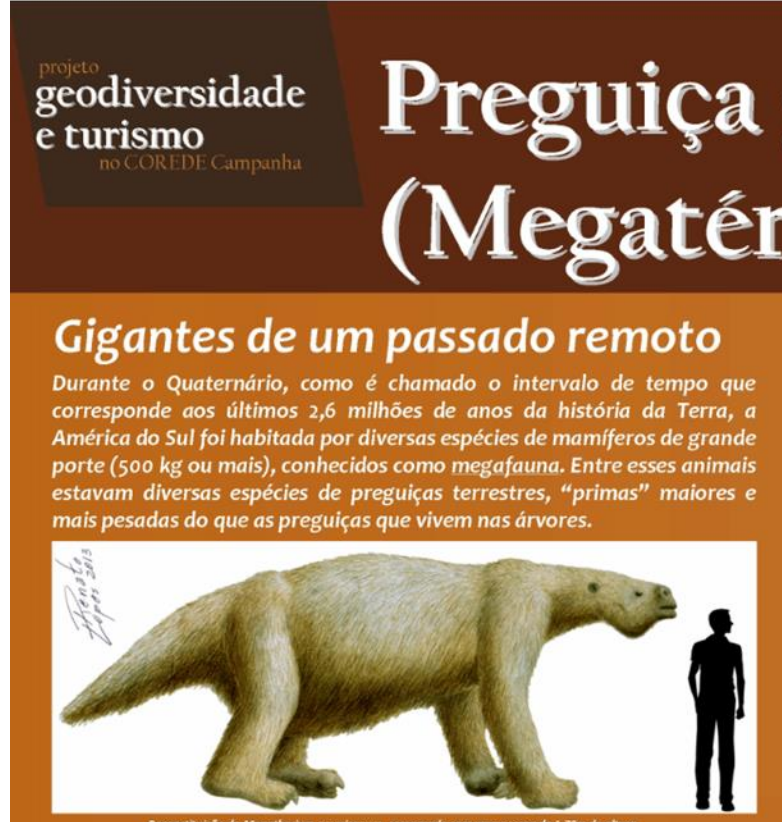

No Século 19, o naturalista dinamarquês Peter Wilhelm Lund descobriu nas cavernas de Minas Gerais fósseis de uma outra espécie de preguiça tão grande quanto o megatério, que foi batizada de Eremotherium laurillardi. Embora o eremotério fosse um animal característico das regiōes clima tropical, também foi encontrado em Caçapava e Santa Vitória, o que indica que em alguma época no passado o clima no sul do Brasil foi mais quente.

Uma característica notável desses animais é que caminhavam nas quatro patas, mas também podiam caminhar apoiados só nas pernas traseiras. En um local chamado Pehuen-có, na Argentina, ficaram preservadas pegadas de megatério, feitas em uma lama que endureceu, e mostram que esses animais caminhavam de forma bipede, como nós. Por isso em muitos museus os esqueletos de megatério e eremotério são montado em pé. Por serem capazes de assumir postura bipede, ficando com as mãos livres, é possivel que esses animais tenham escavado algumas das tocas gigantes (paleotocas) encontradas em diversos locais do Rio Grande do Sul.

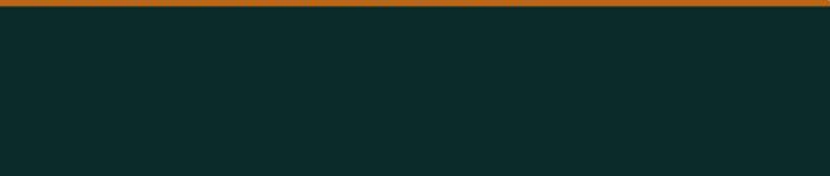

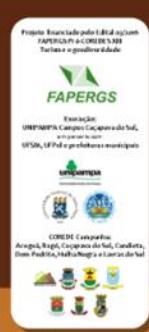

A maior espécie de preguiça que existiu é conhecido como megatério. O primeiro esqueleto deste animal foi encontrado na Argentina no século 18, e batizado pelo naturalista francês Georges Cuvier com nome cientifico Megatherium americanum, que significa "fera gigante da América". Foi o maior mamifero que já viveu na América do Sul, e desapareceu por volta de 10 mil anos atrás.

Existem esqueletos completos de megatério em museus na França, Inglaterra e Argentina. Através deles sabemos que esse animal chegava a medir 6 metros de comprimento (maior que um elefante) e pesar em torno de 4 toneladas. Fósseis de megatério são encontrados na Argentina, Uruguai, Paraguai, Bolivia e Chile. Essa distribuição sugere que o megatério vivia em ambientes relativamente frios, de clima temperado. No Brasil, só foram encontrados fósseis desse animal no Rio Grande do Sul, em Santo Vitória do Palmar e Caçapava do Sul.

\section{Gigantes em duas pernas}

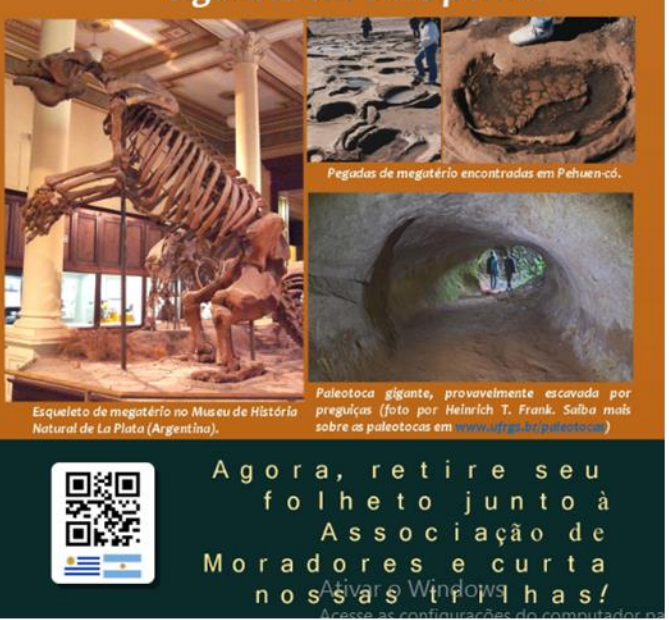

Elaborado pelos autores em 2017

Para avaliar os painéis, os mesmos foram dispostos em corredores nos diferentes andares do Instituto Municipal de Educação, em Caçapava do Sul, sempre em uma altura onde o centro do painel ficasse a 1,20 metro do chão. Em um primeiro momento, houve apenas uma observação à distância, por parte de integrantes do projeto, sem qualquer intervenção ativa, para captar as reações dos estudantes à 
presença física dos painéis. Em um segundo momento, os painéis foram levados às salas de aula de sexto, sétimo e oitavo anos do ensino fundamental. Essas turmas e faixas de escolaridade foram selecionadas exatamente para contemplar o nível de compreensão sugerido pelas pesquisas de Hose (1999) e Nova Scotia (2008).

Em sala de aula, novamente na presença dos painéis interpretativos, que foram fixados nas paredes da sala, os estudantes responderam um questionário anônimo. Os questionários foram aplicados exclusivamente pela(s) professora(s) de geografia ou ciências das turmas selecionadas, sem presença de pesquisadores das universidades responsáveis pelo projeto, exatamente para minimizar eventual constrangimento ou condescendência com o projeto ou com as pessoas que elaboraram os painéis.

O questionário continha diversas perguntas gerais a todos os painéis, a serem respondidas em escala 'tipo Likert', com três ou cinco alternativas, sendo uma de neutralidade. Essas questões perguntavam sobre: (1) as dimensões dos painéis, se eram muito pequenos, grandes demais, ou de tamanho adequado; (2) as cores e tonalidades utilizadas, se eram agradáveis, desagradáveis ou neutras ao olhar; (3) se essas cores e tonalidades combinavam com a paisagem da região ou se eram invasivas em relação a essa; (4) os tamanhos das fontes dos títulos dos painéis, se eram muito pequenos, grandes demais ou de tamanho adequado; (5) da mesma forma, os tamanhos das fontes do corpo dos textos escritos; (6) a presença dos textos em castelhano no painel sobre a Pedra do Segredo, se atrapalhavam a leitura, se eram neutros, ou se estimulavam a apreensão de outro idioma; (7) a proporção entre imagens e textos, se era adequada, se havia imagens demais, ou se havia texto em demasia; (8) a qualidade das imagens utilizadas; e (9) a presença de imagens de fundo, em 'marca d'água', se era visível ou imperceptível, e se era importante ou atrapalhava a leitura.

Além disso, havia duas questões onde os respondentes eram convidados a atribuir notas, na escala de 0 a 10, para: (a) as diferentes combinações de cores do fundo e das letras dos textos; e (b) a disposição dos textos em colunas verticais (duas 
ou três), linhas horizontais, setores não-uniformes ou no interior de círculos, e sua influência sobre a legibilidade. Por fim, havia questões, também em escala 'tipoLikert', específicas para cada painel interpretativo, perguntando se os textos eram interessantes ou pouco interessantes, agradáveis ou cansativos, e fáceis ou difíceis de compreender. Havia, ainda, espaço para manifestações escritas com relação a diferentes temas e características dos painéis.

Os trabalhos de observação das reações e aplicação do questionário foram realizados no mês de agosto de 2018. Após essas etapas, os dados foram compilados e trabalhados em tabelas do software Microsoft@Excel, para obtenção de parâmetros estatísticos básicos, como média aritmética simples, desvio-padrão e moda, ou seja, a nota ou resultado de maior frequência dentro de uma amostra. Esse trabalho objetivou captar as impressões gerais sobre a linguagem e o aspecto visual dos painéis interpretativos preliminares do projeto de geodiversidade e turismo no COREDE Campanha, e propor modificações e adaptações para o layout definitivo.

\section{RESULTADOS E DISCUSSÃO}

Os painéis interpretativos foram posicionados estrategicamente, conforme recomendações de funcionários lotados no Instituto Municipal de Educação, em quatro pontos de passagem frequente de estudantes: no corredor, numa das escadarias, na entrada do refeitório e no pátio interno onde se concentram as atividades do recreio. A movimentação em torno de cada um dos painéis foi observada, pelos responsáveis pelo projeto, durante uma a duas horas, em dois dias consecutivos, totalizando: (a) 60 pessoas passaram pelo painel 'Pedra do Segredo', e 48 interagiram com o painel; (b) 139 estudantes cruzaram pelo local onde estava o painel 'Pedras das Guaritas', com cerca de 45 interações efetivas; (c) 90 pessoas passaram pelo painel 'Minas do Camaquã', com cerca de 65 interações efetivas; e (d) 95 pessoas passaram pelo painel 'Preguiça-gigante', sendo que 28 interagiram com o painel. Mesmo considerando que, em certos momentos, sobretudo no segundo dia, 
algumas turmas vinham acompanhadas do(a) professor(a) especialmente para verem os painéis (o que, na verdade, seria inevitável diante de uma novidade, de cunho científico, no ambiente escolar), os painéis tiveram uma atratividade relativamente boa.

Alguns estudantes observavam os painéis sozinhos, outros em grupos de tamanhos diversificados, durante períodos que variaram muito, entre 5 segundos e 10 minutos. O painel 'Pedras das Guaritas', fixado no acesso ao refeitório, foi aquele observado por menos tempo, nunca passando de 1 minuto e 30 segundos, talvez pelo limitado tempo que os estudantes possuem para o lanche. Os demais painéis foram observados por tempos que variaram de 1 minuto a 10 minutos, com frequência maior de observações entre 2 e 4 minutos, o que vai ao encontro das médias mundiais de observações de painéis. Alguns estudantes inclusive obtiveram, com seus aparelhos de telefonia móvel, fotografias dos painéis, o que reforça a boa impressão e o interesse despertado pelos mesmos.

As informações mais relevantes, no entanto, para os objetivos desta avaliação, referem-se às respostas dos questionários, realizadas em sala de aula, novamente na presença dos painéis preliminares. No total, 72 estudantes responderam o questionário, ainda que nem todos tenham respondido todas as questões e, por isso, algumas questões têm um total de respondentes menor que 72. Quanto às dimensões dos painéis, $86,1 \%$ dos respondentes consideraram adequadas, contra 6,9\% que consideraram os painéis grandes demais, e um mesmo número que os consideraram pequenos demais. Tais resultados demonstram o acerto na definição preliminar do tamanho dos painéis interpretativos. A maioria dos entrevistados considerou que as cores e tonalidades usadas no desenho dos painéis são agradáveis $(54,9 \%)$ ou muito agradáveis $(12,7 \%)$, tendo ainda uma significativa porcentagem de respostas dizendo que são neutras (28,2\%). As respostas que consideraram as cores desagradáveis $(1,4 \%)$ ou muito desagradáveis $(2,8 \%)$ não chegam a somar 5\%. Da mesma forma, uma maioria semelhante considera que essas cores e tonalidades combinam $(52,8 \%)$, combinam perfeitamente $(16,7 \%)$ ou são neutras $(25,0 \%)$ com as 
paisagens da região, enquanto aqueles que pensam que as cores não combinam $(2,8 \%)$ ou mesmo que elas são intrusivas e descaracterizam a região $(2,8 \%)$ são francamente minoritários.

Dessa forma, considera-se que o esquema geral de cores utilizado teve excelente aceitação entre a comunidade escolar consultada. Ainda assim, houve uma série de manifestações espontâneas interessantes, no espaço em branco destinado a responder "que outras cores você acha que poderiam ser utilizadas?", logo após a questão objetiva referente às cores e tons. Quatro respondentes manifestaram desagrado com a cor amarelada do fundo, enquanto dez estudantes sugeriram cores mais escuras no fundo, como verde ou azul escuros. Outros respondentes gostariam de ter visto cores mais vibrantes, como vermelho, o que de certa forma não condiz com regras básicas da interpretação e do desenho de painéis, assim como combinações como "letras vermelhas em fundo verde", manifestada por um estudante, mas inadequadas quando se pensa na população (mínimo 3\% das pessoas) com daltonismo. Uma recomendação, a de usar um verde mais vibrante apenas para chamar a atenção de alguns termos, foi considerada interessante para os painéis finais.

Com relação aos textos, $84,5 \%$ dos estudantes consideraram adequados os tamanhos das fontes dos títulos. Por outro lado, 54,2\% consideraram as fontes do corpo dos textos muito pequenas, contra $45,8 \%$ que as consideraram de tamanho adequado (Fig. 5, em cima, à esquerda). A maioria dos respondentes (75,0\%) considerou a proporção entre texto e imagens adequada, enquanto 23,6\% manifestaram que havia uso excessivo de texto (Fig. 5, em cima, à direita). Essa manifestação de $1 / 4$ das pessoas já pode ser considerada relevante e, juntamente com a percepção de que os textos estavam em fonte pequena, deverá ser considerada na montagem dos painéis finais, onde o texto deverá ser mais sintetizado e escrito em letras um pouco maiores.

Está também relacionada a esse tema a questão sobre a presença de textos em castelhano, exclusivamente no painel da Pedra do Segredo. Mesmo que 48,6\% dos 
estudantes tenham se manifestado a favor da manutenção dos textos em dois idiomas, há uma importante parcela $(25,0 \%)$ que afirmam que esses textos atrapalham a leitura, e que deveriam ser suprimidos (Fig. 5, embaixo). Considerando que os textos em castelhano deveriam ser ainda menores (em termos de fonte a ser usada) que os textos em português, parece mais sensato deixar essa opção (importante, conforme salientado já por Borba et al., 2013) como um QR-code nos painéis, para acesso remoto digital, e não como textos inseridos no painel físico.

As fotografias ou ilustrações foram consideradas de excelente (82\%) ou boa (18\%) qualidade por todos os estudantes, enquanto a imagem de fundo, em 'marca d'água', teve um resultado mais diversificado. Do total de respondentes, 41,7\% consideraram que a marca d'água era visível e importante, conferindo identidade ao painel. Outros 38,9\% manifestaram que nem haviam percebido a imagem de fundo, enquanto $15,3 \%$ haviam percebido a imagem, mas não a consideravam importante. Apenas 4,1\% dos estudantes recomendaram a eliminação da marca d'água, por eventualmente atrapalhar a leitura do texto.

Quanto às combinações de cores, conforme descrito na metodologia, os respondentes deram notas de 0 a 10 para todas as combinações existentes nos painéis preliminares. A combinação de melhor nota apresenta letras brancas sobre um fundo azul-esverdeado-escuro, com nota 8,25, desvio-padrão de 1,95 e moda 10. A segunda foi de letras brancas sobre um fundo castanho, com 7,93, desvio-padrão de 2,41 e moda 10. A combinação que traz maior dificuldade de leitura, segundo os respondentes, é a de letras amarelas sobre fundo alaranjado, com nota 4,08, desviopadrão de 2,64 e moda 1. Outras combinações (letras brancas sobre fundo alaranjado, letras castanhas sobre fundo alaranjado, e letras amarelas sobre fundo azul-esverdeado-escuro) foram avaliadas de maneira razoável, com notas em torno de 6. 
Figura 5 - Gráficos tipo 'pizza' para respostas a questões selecionadas, com respeito ao tamanho das fontes, à proporção imagens/texto e à presença, exclusivamente no painel da Pedra do Segredo (PS), de textos em português e castelhano no mesmo painel. Discussão no texto

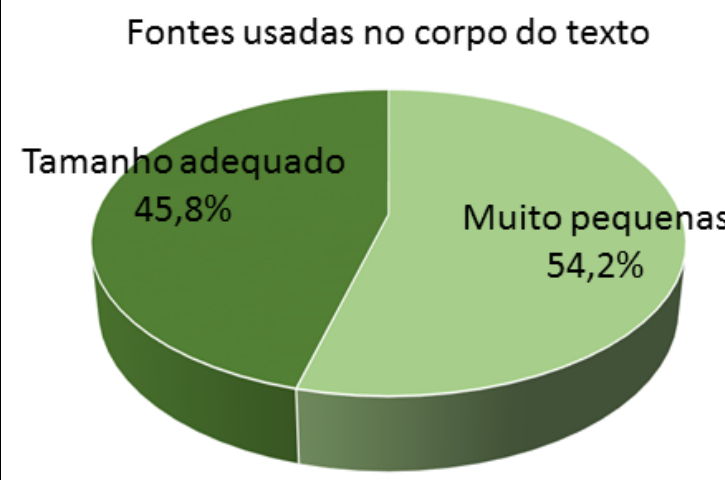

\section{Proporção imagens/texto}

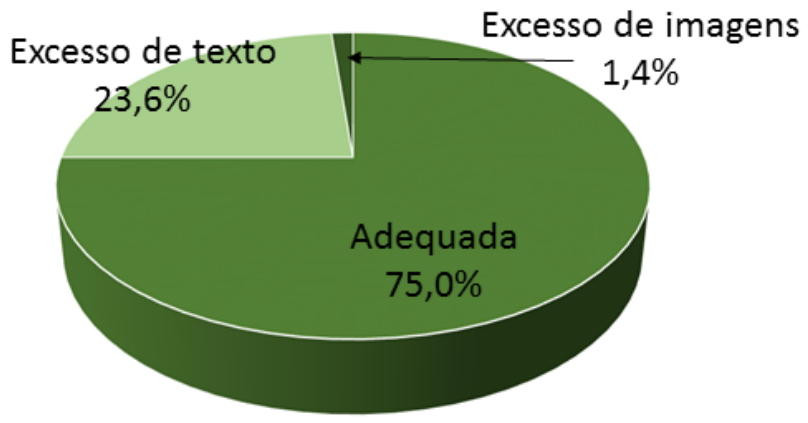

Textos em castelhano (PS)

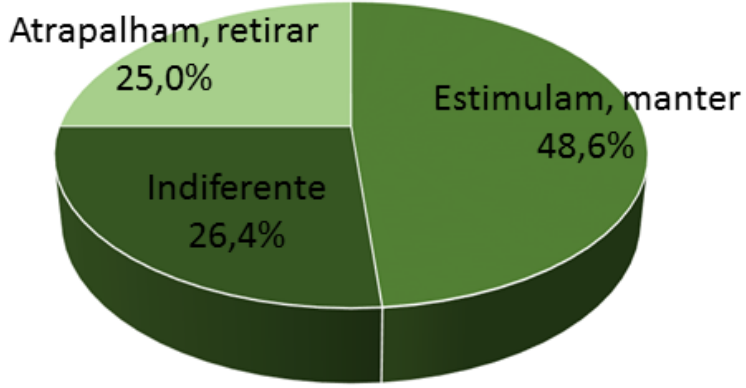

Fonte: Elaborado pelos autores

Os arranjos ou disposições dos textos tiveram um resultado bem mais equilibrado. O arranjo em duas colunas, justificadas, teve a preferência dos estudantes, com nota 8,17 e moda 10. O texto centralizado, dentro de círculos, teve nota 7,92 e também moda 10. O texto distribuído em três colunas, alinhadas segundo a coluna em que estão, como no painel das 'Minas do Camaquã', teve nota final 7,01 e também moda 10. O arranjo horizontal em linhas longas e a distribuição em setores não-uniformes receberam as menores notas, mas em torno de 6 (modas 5 e 7, respectivamente), podendo também ser usados eventualmente. Em conjunto com as 
recomendações, já citadas acima, de que cores mais escuras deveriam ser usadas como fundo, optou-se por desenhar os painéis finais com fundo azul-esverdeadoescuro, letras majoritariamente brancas, e destaques em um verde claro, vibrante. Além disso, a tarja horizontal inferior, que era azul-esverdeada, num tom bem escuro, foi substituída por um azul claro, mais chamativo, conforme sugestões de alguns estudantes. Por fim, os caracteres dos textos escritos, ainda na fonte 'Candara', foram aumentados de tamanho, de 40 para 42 pontos e, nas legendas, de 24 para 26 pontos, melhorando a legibilidade dos painéis, o que se confirma ao se observarem os painéis já instalados (Fig. 6).

Por fim, é importante salientar os resultados relativos ao conteúdo escrito dos painéis interpretativos. O painel melhor avaliado, nesse quesito, foi o das 'Minas do Camaquã', considerado por $87,3 \%$ dos respondentes como “interessante e agradável de se ler". Esse resultado tem também a influência das próprias informações do patrimônio mineiro da localidade, mais próximo da realidade pessoal ou familiar dos estudantes do que informações geológicas, geomorfológicas ou paleontológicas, assuntos dos demais painéis. Ainda assim, o painel da 'Pedra do Segredo' foi considerado interessante e agradável por $82,9 \%$ dos respondentes, enquanto o painel das 'Pedras das Guaritas' teve 77,46\% nessa alternativa. O painel do 'Megatério Preguiça gigante' foi o painel de avaliação menos favorável, com 69,4\% para a alternativa "interessante e agradável de se ler". Quase um quarto das pessoas (23,6\%) consideraram aquele painel como "cansativo e difícil de se ler" (Fig. 7) enquanto, nas manifestações espontâneas por escrito, 6 pessoas manifestaram dificuldades com termos como "Quaternário", "megatério", com nomes estrangeiros dos descobridores dos fósseis, ou com os próprios nomes científicos ali expostos. Talvez uma mudança de abordagem, focalizando mais as características do animal, algumas curiosidades, com menos ênfase a seus descobridores, poderá contribuir para melhorar o entendimento e a atratividade do painel e da própria temática. 
Figura 6 - (A) Novo desenho (layout) dos painéis interpretativos do projeto de divulgação do geoturismo no COREDE Campanha, com textos e títulos em cor branca, com leve aumento do tamanho das letras, sobre um fundo azul-esverdeadoescuro, destaques em verde vibrante, e tarja inferior em azul-claro, também mais vibrante. Painéis já instalados no Parque Municipal da Pedra do Segredo (B) e na área do Forte Dom Pedro II (C), ambos em Caçapava do Sul

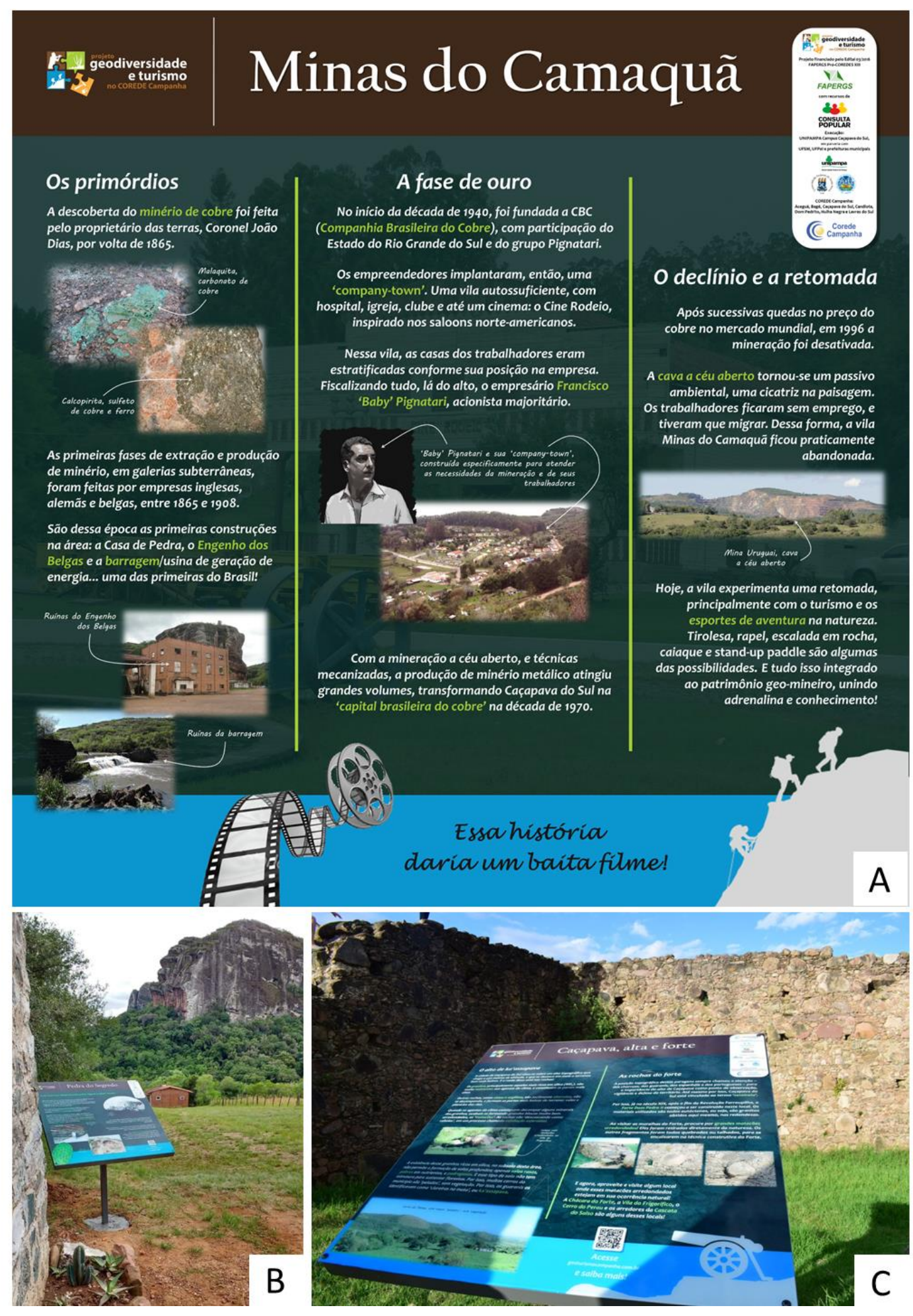

Fonte: (A) Elaborado pelos autores; (B, C) Fotografias obtidas pelos autores, em março de 2019 
Figura 7 - Gráfico tipo 'pizza' para as avaliações da linguagem utilizada no painel 'Preguiça-gigante - Megatério', o único que proporcionou alguma dificuldade na compreensão geral das informações expostas no painel. Discussão no texto

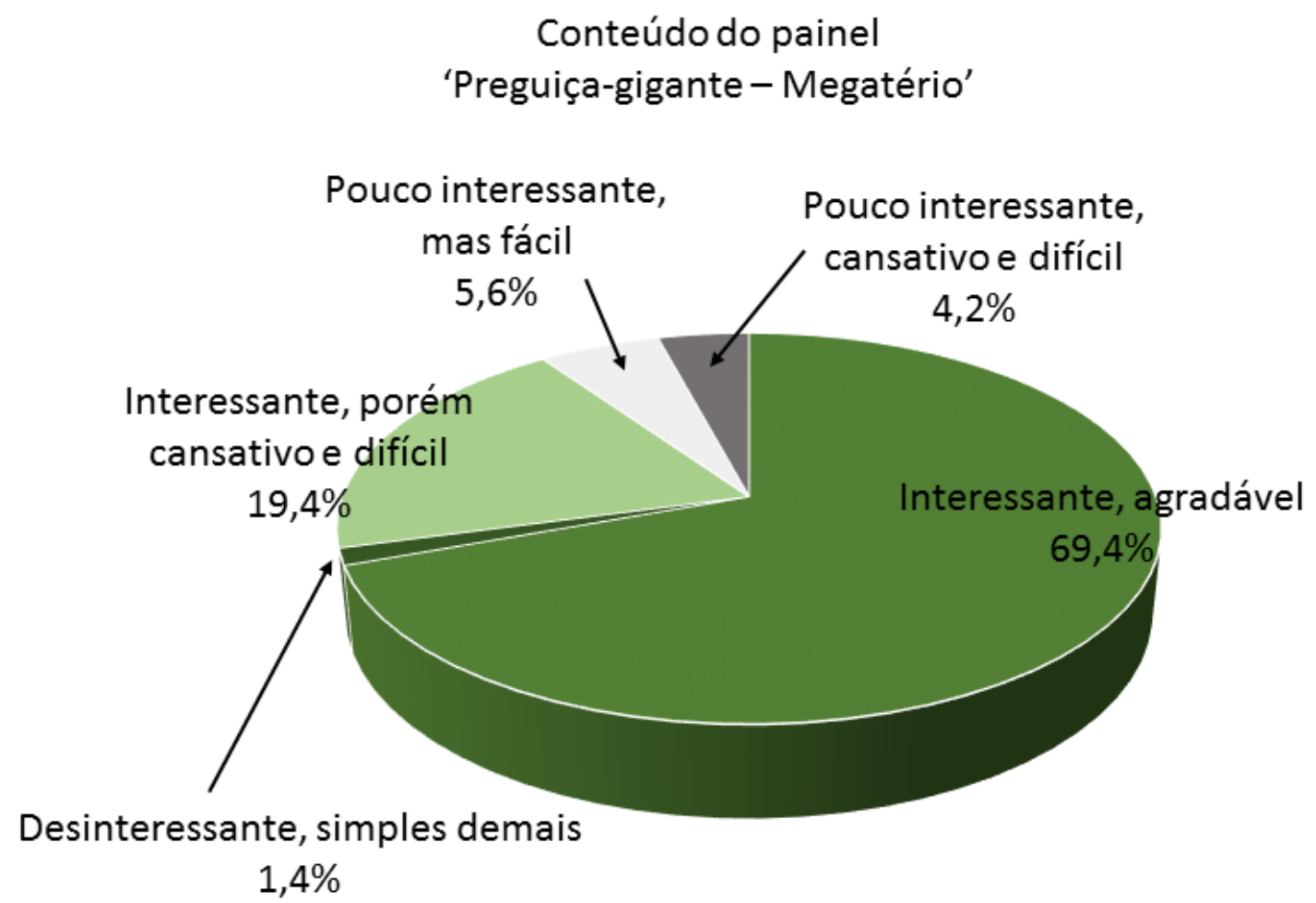

Fonte: Elaborado pelos autores

\section{CONSIDERAÇÕES FINAIS}

Avaliar preliminarmente o conteúdo e os aspectos visuais de painéis interpretativos em fase de design/produção é uma etapa de fundamental importância para qualquer estratégia de (geo)comunicação de fatos, materiais, modelos ou interpretações relacionadas à área das geociências. A tradução da complexa e, por vezes, hermética linguagem da geologia, da geomorfologia e, de maneira geral, das ciências ambientais, é um exercício interessante do ponto de vista da pesquisa científica, mas que traz também reflexos relevantes para o ensino e a extensão do conhecimento à sociedade. Por isso, trazer a comunidade, especialmente a escolar, ao seio dessa atividade de pesquisa, é uma iniciativa capaz de incrementar e melhorar a qualidade da interpretação e, consequentemente, da compreensão da 
mensagem geopatrimonial. Além disso, já serve como estímulo a que esse conjunto de estudantes participantes da avaliação se interesse por tais informações, e deseje ver os resultados de seu trabalho nas praças, nos parques, nos geomonumentos.

A avaliação dos estudantes foi responsável por uma série de modificações essenciais nos painéis. A cor de fundo escura, a cor branca e o tamanho maior (de 40 para 42) das fontes do texto, a cor verde dos destaques, e a cor azul clara vibrante da tarja inferior dos painéis, hoje já instalados em sua grande maioria, foram características adotadas após a avaliação pelos estudantes. Essas mudanças incrementaram a atratividade e a visibilidade dos painéis em meio aos cenários em que foram implantados, bem como facilitaram a leitura do conteúdo. Além disso, os alertas feitos pelos estudantes sobre termos técnicos, nomes científicos ou informações não essenciais, foram importantes na adoção de novos textos (ou de novos trechos de textos), explicando termos complicados e suprimindo alguns tópicos. A interpretação realizada ganhou qualidade com a intervenção dos estudantes consultados.

A partir da efetiva implantação dos painéis interpretativos, sugere-se que haja novas etapas de pesquisa, no sentido de avaliar: (1) a real atratividade e visibilidade dos painéis após instalados, que pode ser bem diferente da percepção obtida em corredores de uma escola; (2) a correção do ângulo de instalação e da altura, considerando a média da população acima de 11 anos de idade; (3) a real legibilidade dos painéis e de seus componentes gráficos (textos e ilustrações) frente a fatores como insolação, reflexos, locais com sombras de árvores, etc.; e (4) as impressões de novas populações, como a de visitantes ou adultos da comunidade local, além de outras turmas de estudantes, sobre os painéis interpretativos. Informações como essas poderão, no futuro, melhorar ainda mais a qualidade dos meios de interpretação, assim como da estratégia de geoconservação e geoturismo como um todo. 


\section{AGRADECIMENTOS}

Os autores agradecem o auxílio financeiro da Fundação de Amparo à Pesquisa do Estado do Rio Grande do Sul (Fapergs), através do projeto 16/2551-0000383-1, contemplado no Edital Fapergs Pró-COREDE Campanha. Reconhecem também a importante participação da população do COREDE Campanha, que elegeu o geoturismo como uma de suas prioridades de investimento na Consulta Popular de 2015. Por fim, agradecem à direção, ao corpo docente e aos estudantes do Instituto Municipal de Educação Augusta Maria de Lima Marques, em Caçapava do Sul, especialmente àqueles que participaram da avaliação aqui relatada.

\section{REFERÊNCIAS}

\section{ALDRIDGE, D. Mejora de la Interpretación de los Parques y la Comunicación con} el Público. UICN (ed.), Segunda Conferencia Mundial sobre Parques Nacionales; Yellowstone y Grand Teton, EE.UU., 18-27 septiembre de 1972. Informe No. 25, 1973.

BAZÁN, H.G. El Mensaje de los Paneles Interpretativos y el Aprovechamiento Turístico y Educativo del Patrimonio Natural. Macla, Revista de la Sociedad Española de Mineralogia, v. 17, p. 57-58, 2013.

BAZÁN, H.G. La Interpretación del Patrimonio como estrategia para la educación y socialización del patrimonio en el medio rural. Monográfico, v. 9, p. 21-40, 2014.

BORBA, A.W.; FIGUEIRÓ, A.S.; GARCIA, T.S.; DOMINGUES, S.A.; SOUZA, L.P.M. Peculiaridades da 'metade sul' gaúcha e suas implicações para a geoconservação, o geoturismo e os geoparques. Geonomos, v. 21, n. 2, p. 79-83, 2013.

BORBA, A.W.; SILVA, E.L.; SOUZA, L.P.M.; SOUZA, L.F.; MARQUES, R.V. Relação entre a geodiversidade intrínseca e a estruturação de habitat na escala do geossítio: exemplos na Serra do Segredo e nas Pedras das Guaritas (Caçapava do Sul, RS, Brasil). Pesquisas em Geociências, v. 43, n. 2, p. 183-202, 2016.

BORBA, A.W.; GUADAGNIN, F.; MATTÉ, V.; CARON, F.; FERREIRA, P.F.; KUMAIRA, S.; LOPES, R.P.; SELL, J.C.; DEGRANDI, S.M.; CORRÊA, A.P.S.; SILVA, E.L.; SOUZA, L.P.M.; URBAN, C.; SIMON, A.L.H.; BALDUÍNO, E.; RIZZATTI, M. Geoturismo na área de abrangência do COREDE Campanha ('metade sul' do Rio Grande do Sul, Brasil), parte I: geomonumentos de interesse turístico. Terr@ Plural, v. 13, n. 2, p. 469-495, 2019 a. 
BORBA, A.W.; GUADAGNIN, F.; MATTÉ, V.; CARON, F.; FERREIRA, P.F.; KUMAIRA, S.; LOPES, R.P.; SELL, J.C.; DEGRANDI, S.M.; CORREAA, A.P.S.; SILVA, E.L.; SOUZA, L.P.M.; URBAN, C.; SIMON, A.L.H.; BALDUÍNO, E.; VARGAS-PEIXOTO, D. Geoturismo na área de abrangência do COREDE Campanha ('metade sul' do Rio Grande do Sul, Brasil), parte II: elementos geopatrimoniais ex situ, contextos e identidades. Terr@ Plural, v. 13, n. 2, p. 496-512, 2019b.

DOMINGUES, S.A. Patrimônio geo-mineiro da localidade de Minas do Camaquã (Caçapava do Sul, RS). Dissertação de Mestrado. Programa de Pós-Graduação em Geografia. Universidade Federal de Santa Maria. 135p. 2016.

HOSE, T. Geoturismo europeo. Interpretación geológica y promoción de la conservación geológica para turistas. In Barettino, D., Vallejo, M. y Gallego, E. (Eds.). Patrimonio Geológico: Conservación y Gestión. Sociedad Geológica de España, Instituto Tecnológico Geominero de España y European Association for the Conservation of the Geological Heritage: Madrid, 1999.

LUZ, F.G.; MOREIRA, J.C. Geoturismo aliado a painéis interpretativos: uma proposta para o Buraco do Padre, Ponta Grossa (PR). Revista Nordestina de Ecoturismo, Aquidabã, v. 3, n. 2, p. 18-30, 2010.

MEIRA, S.A.; BRITO, D.S.; MORAIS, J.O. Interpretação Ambiental e Geodiversidade: Proposta de um Painel Interpretativo sobre o Geossítio Pedra Furada, Parque Nacional de Jericoacoara, Ceará. Espaço Aberto, PPGG-UFRJ, v. 6, n. 2, p. 9-27, 2016.

MORALES MIRANDA, J. La interpretación ambiental y la gestión del medio. In Comunicações e apresentações - I Jornada de Educação Ambiental. Direção Geral de Meio Ambiente. Barcelona, 1983.

MOREIRA, J.C. Interpretative panels about the geological heritage - a case study at the Iguassu Falls National Park (Brazil). Geoheritage, v. 4, p. 127-137, 2012.

MOREIRA, J.C. Geoturismo e Interpretação Ambiental. Ponta Grossa: Editora UEPG, 2014, 157 p.

NOVA SCOTIA. Outdoor Interpretive Signage - Your Guide to Connecting People and Places. Tourism Development 'How to Guide', 52 p., 2008, disponível em https://tourismns.ca/sites/default/files/2017-01/interpretive_guide_0.pdf, acesso em 18/12/2018.

RISK, P.H. The Interpretive Talk. In: SHARPE, G. (ed.), Interpreting the Environment, Wiley \& Sons. London. 1982.

SELL, J.C. Estradas paisagísticas: estratégia de promoção e conservação do patrimônio paisagístico do pampa Brasil-Uruguai. Tese de Doutorado, Universidade Federal de Santa Maria (UFSM), 2017, 321 p. 
22| Avaliação da linguagem e aspectos visuais de painéis interpretativos turísticos para geomonumentos e outros elementos geopatrimoniais do corede campanha, RS, Brasil

TILDEN, F. Interpreting Our Heritage. The University of North Carolina Press, Chapel Hill. North Carolina, 1957. 